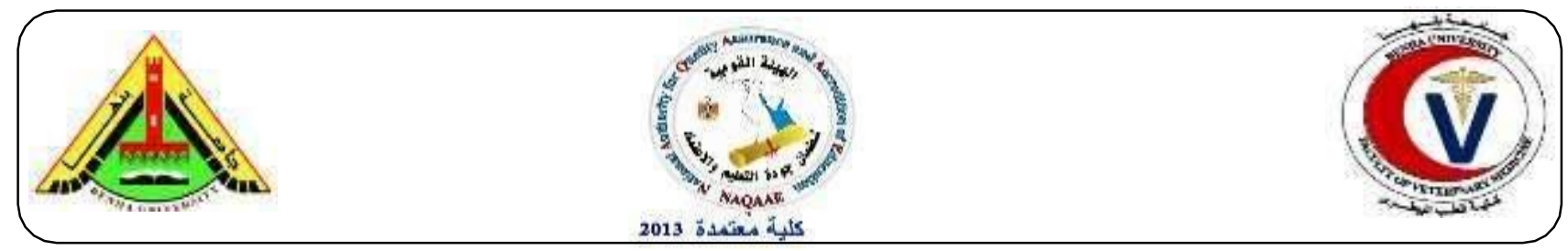

\title{
Mycobiota of some meat products and spices
}

\author{
${ }^{1}$ Ashraf, A. Abd El- Tawab., ${ }^{2}$ Eman, M. El-Diasty., ${ }^{3}$ Dalia, F. Khater. and ${ }^{3}$ Yahya M. Al-baaly. \\ ${ }^{1}$ Department of Bacteriology, Immunology and Mycology, Faculty of Veterinary Medicine, Benha University. \\ ${ }^{2}$ Department of Mycology, Animal Health Research Institute Dokki, Giza. \\ ${ }^{3}$ Animal Health Research, Tanta Branch.
}

\section{A B STR A CT}

This work was carried out to evaluate the fungal quality of some meat products and spices sold in different groceries and supermarkets in Gharbia Governorate under different trade names. A total of 60 random samples of kofta and burger ( 30 of each) and 66 samples of kofta spices and burger spices (33 of each). The results revealed that the mould could be detected in, 27/30 (90\%), 27/30 (90\%), 33/33 (100\%) and 30/33 (90.9\%) in examined kofta, burger, kofta spices and burger spices, respectively. The most frequently isolated mould species from samples was Aspergillus spp. with incidence of 36/42 (85.71\%) in kofta, 46/79 (58.23\%) in burger, 86/155 (55.48\%) in kofta spices and 66/114 (57.89\%) in burger spices followed by Penicillium spp. 6/42 (14.29\%) and 12/79 (15.18\%), 24/155 (15.48\%) and 21/114 (18.44\%), respectively. Other identified mould isolates were Acremonium, Cladosporium, Geotrichum, Mucor, Claveolaria, Emericella nudulans, Eurotium, Fusarium and Scorulopsis. Aflatoxin B1 could be detected in one sample of kofta and 6 samples of spices with a mean value of 0 and $9.6 \pm 2.2 \mu \mathrm{g} / \mathrm{kg}$. Aflatoxin B1could not be detected in examined burger. As conclusion Kofta, burger and their spices highly contaminated with Aspergillus spp and Penicillium spp which may gain access during the manufacturing process or food additives leading to high economic losses and have a public health hazard due to the production of aflatoxins.

Key words: meat products, spices, moulds, Aspergillus, Aflatoxin.

\section{INTRODUCTION}

Meat products are considered as an ideal culture medium for growth of many organisms (Fratmico et al., 2005). The increase in the production of processed foods and high demand for meat is the major reason behind the rapid increase in spices consumption (Little et al., 2003).

Meat products are gaining popularity because they represent quick easily prepared meals of low price from one side and render the processors to convert the various types of meat into unified products from the other side. Also, raw foods can transmit pathogens to utensils and equipment which they contact to them as well as workers who handled raw food can transfer microorganisms from raw foods to cook.

Moulds can cause deterioration of meat and meat products through production of proteolytic and lipolytic enzymes leading to discoloration, poor appearance and off-flavor (Koburger and Marth, 1984). Contamination of meat products with different mould species considers a real hazard as it affecting the quality of these meat products by 
increasing the opportunity for its spoilage and deterioration (Alcaide-Molina et al., 2009). Mould growth can cause food losses due to deterioration, and adverse health effects due to toxin production. Conidia and asexual spores are the main factors of dispersal and infection in most food-relevant moulds. Food spoilage by filamentous fungi is a global issue of great significance (Svanström, 2013).

Mycotoxins are toxic substances elaborated by filamentous fungi. They constitute a heterogeneous group of secondary metabolites with diverse potent pharmacological and toxic effects in human and animals. More than 300 secondary metabolites have been identified but around 30 are real concern for human and animal health. The toxicity may be acute after exposure to one high dose or chronic after repeated exposure to weak doses (Bennett and Klich, 2003). The most important mycotoxins are produced by moulds belonging to Aspergillus, Penicillium and Fusarium spp (Bhatnagar et al., 2002). So, this study aimed to detect the mycobiota and Aflatoxin B1 in meat product (kofta and burger) and their spices.

Aflatoxins named as aflatoxin B1, B2, G1 and G2 of are synthesized by A. flavus and A. parasiticus. These aflatoxins can often be found in many herbal products such as cereals, peanuts, cotton seeds, dried fruits, spices (Isleyici, 2017). Optimal conditions for of A.parasiticus and A. flavus to produce toxin are reported to be 16-31 ${ }^{\circ} \mathrm{C}$ and 0.83-0.99 aw (Peromingo et al., 2016). The Food and Agriculture Organization (FAO) determined the maximal daily intake of aflatoxin $\mathrm{B} 1$ to be $5 \mu \mathrm{g} / \mathrm{kg}$ and the total aflatoxin (B1 + B2 $+\mathrm{G} 1+\mathrm{G} 2)$ to be $10 \mu \mathrm{g} / \mathrm{kg}$. This toxin has been classified by the International Agency for Research on Cancer (IARC) (2010), in carcinogenic effect Group 1.

The increase in the production of processed foods and high demand for meat is the major reason behind the rapid increase in spices consumption (Little et al., 2003). Spices are largely produced in countries where tropical climates are favorable to mycotoxin contamination. Furthermore, they are usually dried on the ground in the open air in poor hygienic conditions that even more promote growth of mold and production of mycotoxin (Martins et al., 2001).
Spices used in meat products can be shown as a source of mycotoxin contamination of those products. Pleadin et al. (2015) reported that they found aflatoxin in their products because of the presence of aflatoxin residues in red pepper and black pepper, although mycotoxin was not found in the meat they used as raw material in experimental sausage production. So, this study aimed to detect the mycobiota and Aflatoxin B1 in meat product (kofta and burger) and spices.

\section{MATERIALS AND METHODS}

\section{Samples:}

A total of 60 random samples of kofta and burger (30 of each) and 66 samples of kofta spices and burger spices (33 of each) were purchased from different groceries and supermarkets in Gharbia Governorate. The collected samples were kept in sterile polyethylene bags and preserved in an ice box then transferred to the laboratory under complete aseptic condition without undue delay to be examined mycologically.

\section{Mycological examination:}

\subsection{Sample preparation (APHA, 2001):}

Twenty five grams from each sample were carefully and aseptically homogenized in a blender with $225 \mathrm{ml}$ of sterile peptone water $0.1 \%$ to form a dilution of 1:10, from which tenth fold serial dilutions were accomplished up to 106.

\subsection{Mould count (ISO 21527, 2008):}

One $\mathrm{ml}$ of the previously prepared serial dilution was separately poured into duplicated Petri dishes carefully and mixed with Dichloran Rose Bengal Chloramphenicol (DRBC) agar, incubated at $25^{\circ} \mathrm{C}$ for 5-7 days.

\subsection{Isolation and Identification of mould (Pitt and Hocking, 2009):}

The isolated colonies were picked up from the DRBC agar into slope Sabroud dextrose agar (SDA) and incubated at 250c for 5-7 days after this transferred on malt extract (MEA) and Czapek yeast agar (CYA) plates for identification. 


\subsection{Macroscopical examination:}

The macroscopical examination of mould colonies includes the rate and pattern of growth, as color, texture, basal and surface mycelia and the rate of colony growth and diameter using a magnifying hand lens.

\subsection{Microscopical examination}

It was carried out according to Wet mount slide method (Arx Von 1967):

\subsection{Aflatoxin Blresidues in meat products and} spices:

Mycotoxins were extracted from the collected kofta, burger and their spices according to the methods described by (Stubblefield et al., 1982). Chromatographic plates were examined for qualitative estimation of Aflatoxins. Colors and intensities of the unknown spots were compared with those of the standard reference Aflatoxin B1 according to (Scott, 1965). Samples extracts which were found to contain mycotoxins by the qualitative technique were further estimated quantitatively according to (Gabal et al., 1994).

\section{RESULTS}

The result recorded in Table (1) showed that incidence of mould in the examined meat products samples were; $(90 \%)$ and $(90 \%)$ of both kofta and burger samples, respectively. while in spices were $100 \%$ and $90.90 \%$, respectively.

Results achieved in Table (2), the predominant isolated genera was Aspergillus species with incidence of $(85.71 \%),(56 \%)$ followed by Penicillium species (14.29\%) and (15.18\%) in kofta and burger samples, respectively. Mucor species (11.42\%), Geotrichum spp (7.59\%), Cladosporium spp (3.79\%) and Acremonium spp $(3.79 \%)$ were detected in burger samples only. While in spices samples were contaminated with many mould genera. The predominant mould genera isolated from kofta spices and burger spices samples were Aspergillus species (55.48\%) and (57.89\%), Penicillium (15.48\%) and (18.44\%), Mucor spp (13.55\%) and (7.89\%), Cladosporium spp (5.80\%) and (5.26\%), Eurotium spp (0\%) and (7.89\%), Fusarium spp $(0 \%)$ and $(2.63 \%)$, Acremonium spp (1.94\%) and $(0 \%)$, Scorulopsis $(3.87 \%)$ and $(0 \%)$, Claveolaria and Emericella.nudulans (1.94\%) and (0\%) in kofta and burger, respectively.

The prevalence of Aspergillus species in both meat product samples were A.flavus (33.33\%), $(32.61 \%)$ followed by A. niger $(66.67 \%)$ and $(32.61 \%)$, while A. clavatus $(19.57 \%)$, A. sydowii $(8.69 \%)$ and A. Ochraceus $(6.52 \%)$ detected in burger samples only. While in kofta and burger spices, they were $(6.98 \%)$ \& (13.64\%), (2.32\%) \& (4.55\%), (34.88\%) \& $(27.26 \%), \quad(6.98 \%) \quad \& \quad(0 \%), \quad(34.88 \%) \quad \&$ $(36.36 \%),(10.47 \%) \&(13.64 \%),(3.49 \%) \&$ $(0 \%)$ and $(0 \%) \&(4.55 \%)$ for A.carbonareus, A. clavatus A. flavus, A. fumigatus, A. niger, A. ochraceus, A.sydowii and A.ustus, respectively. (Table 3)

Regarding the results tabulated in Table (4) Aflatoxin B1 was detected in one sample (3.33\%) of kofta and 6 samples $(9.09 \%)$ of spices. The minimum detected level of aflatoxin B1 in and kofta was $2.6 \mu \mathrm{g} / \mathrm{kg}$. and in spices samples, was $4.7 \mu \mathrm{g} / \mathrm{kg}$, where maximum were $13.1 \mu \mathrm{g} / \mathrm{kg}$ with a mean value of $9.6 \pm 2.2 \mu \mathrm{g} / \mathrm{kg}$. Aflatoxin B1 failed be detected in examined burger samples.

Table (1): Incidence of moulds isolated from the examined meat products and spices

\begin{tabular}{cccc}
\hline Samples & $\begin{array}{c}\text { No. of } \\
\text { Examined samples }\end{array}$ & $\begin{array}{c}\text { No. of } \\
\text { +ve samples }\end{array}$ & $\%$ \\
\hline Kofta & 30 & 27 & 90 \\
Burger & 30 & 27 & 90 \\
kofta spices & 33 & 33 & 100 \\
burger spices & 33 & 30 & 90.90 \\
\hline
\end{tabular}


$\%$ according to number of examined samples for each type of samples

Table (2): Incidence of mould genera isolated from different examined meat products and spices samples.

\begin{tabular}{lcccccccc}
\hline Isolated mould & \multicolumn{2}{c}{ kofta } & \multicolumn{2}{c}{ Burger } & \multicolumn{2}{c}{ kofta spices } & \multicolumn{2}{c}{ burger spices } \\
& No & $\%$ & No & $\%$ & No & $\%$ & No & $\%$ \\
\hline Aspergillus spp & 36 & 85.71 & 46 & 58.23 & 86 & 55.48 & 66 & 57.89 \\
Acremonium spp & - & & 3 & 3.79 & 3 & 1.94 & - & - \\
Cladosporium spp & - & - & 3 & 3.79 & 9 & 5.80 & 6 & 5.26 \\
Claveolaria & - & - & - & - & 3 & 1.94 & - & - \\
Emericella. Nudulans & - & - & - & - & 3 & 1.94 & - & - \\
Eurotium spp & - & - & - & - & - & - & 9 & 7.89 \\
Fusarium spp & - & - & - & & - & - & 3 & 2.63 \\
Geotrichum spp & & & 6 & 7.59 & - & - & - & - \\
Penicillium spp & 6 & 14.29 & 12 & 15.18 & 24 & 15.48 & 21 & 18.44 \\
Mucor spp & - & - & 9 & 11.42 & 21 & 13.55 & 9 & 7.89 \\
Scorulopsis & - & - & - & - & 6 & 3.87 & - & - \\
Total & 42 & 100 & 79 & 100 & 155 & 100 & 114 & 100 \\
\hline \% according to total number of isolates for each type of samples &
\end{tabular}

Table (3): Frequency percentage of the isolated Aspergillus species in the examined meat products and spices samples

\begin{tabular}{|c|c|c|c|c|c|c|c|c|}
\hline Isolated & \multicolumn{2}{|c|}{ Kofta } & \multicolumn{2}{|c|}{ burger } & \multicolumn{2}{|c|}{ kofta spices } & \multicolumn{2}{|c|}{ Burger spices } \\
\hline Aspergillus species & No & $\%$ & No & $\%$ & No & $\%$ & No & $\%$ \\
\hline A. carbonarius & - & - & & & 6 & 6.98 & 9 & 13.64 \\
\hline A. clavatus & - & - & 9 & 19.57 & 2 & 2.32 & 3 & 4.55 \\
\hline A. flavus & 12 & 33.33 & 15 & 32.61 & 30 & 34.88 & 18 & 27.26 \\
\hline A. fumigatus & - & - & & & 6 & 6.98 & - & - \\
\hline A. niger & 24 & 66.67 & 15 & 32.61 & 30 & 34.88 & 24 & 36.36 \\
\hline A. Ochraceus & - & - & 3 & 6.52 & 9 & 10.47 & 9 & 13.64 \\
\hline A. sydowii & - & - & 4 & 8.69 & 3 & 3.49 & - & - \\
\hline A. ustus & - & - & & & - & - & 3 & 4.55 \\
\hline Total & 36 & 100 & 46 & 100 & 86 & 100 & 66 & 100 \\
\hline
\end{tabular}


Table (4): Incidence of aflatoxin $B_{1}$ in meat products and spices:

\begin{tabular}{rcccc}
\hline Type of sample & Number of positive samples & Min & Max & Mean + SE $\mu \mathrm{g} / \mathrm{kg}$ \\
Kofta & 1 & 2.6 & - & - \\
Burger & 0 & - & - & - \\
Spice & 6 & 4.7 & 13.1 & $9.6 \pm 2.2$ \\
\hline
\end{tabular}

Table (5) Acceptability of Aflatoxin B1 concentration $\mu \mathrm{g} / \mathrm{kg}(\mathrm{ppb})$ in examined samples

\begin{tabular}{lcccc}
\hline Samples & \multicolumn{1}{l}{$\begin{array}{l}\text { No. of } \\
\text { Examined samples }\end{array}$} & $\begin{array}{l}\text { Permissible } \\
\text { Limits }(\mathrm{ppb})^{*}\end{array}$ & \multicolumn{2}{c}{ Accepted samples } \\
& 30 & 15 & 30 & $\%$ \\
\hline Kofta & 30 & 15 & 30 & 100 \\
Burger & 66 & 15 & 66 & 100 \\
Spice & & 15 & 100 \\
\hline
\end{tabular}

*Permissible limit according to WHO "15 ppb" (Jelinek et al., 1989)

\section{DISCUSSION}

Mould species can grow on a wide variety of meat products, as they can tolerate elevated temperature and reduced water activity, as well as, their spores are longer lived and more resistant to chemicals (Pitt and Hocking, 2009).

In recent years, there has also been a steady increase in the production and consumption of processed meat products worldwide because of their high nutritive value and convenience (Rajic et al., 2007).

The obtained results in table (1) were nearly similar to that obtained by (Hussein, 2008) who reported that the incidence of mould in kofta and burger was (93.3\% and $86.6 \%$ ), respectively. However this incidence was higher when compared with that recorded with (Saleh and Salah El-Dien 2006) who found that the incidence of mould in burger was $35 \%$ and (Lamada and Nassif 2008) who reported an incidence of $60 \%$ in kofta. Such variations may be attributed to the unsanitary measures and the difference in the hygienic condition under which the meat products were prepared. Contamination may come from air and water used for washing and rinsing of equipments. Also, the plant itself may be due to difference in manufacture practice, handling from producers to consumers and the effectiveness of hygienic measures applied during production (Gaafer, 2009).

Spices have been used in many industries, with the food industry and catering being predominant users. Having been dried material from plant origin, spices are commonly heavily contaminated with xerophilic storage moulds and bacteria. The most frequent fungal contaminants of spices are species from the genera Aspergillus and Penicillium. (Kocic' -Tanackov et al., 2007). It is evident from the results recorded in table (1) that the samples of spices are highly contaminated with moulds. These results were nearly similar to that obtained by (El-Ghreeb et al., 2013) who declared that $100 \%$ the spices were contaminated by mould.

Mould contamination in food is a useful indicator to evaluate the food quality, the degree of deterioration is an essential component for microbiological assurance programs (Taniwaki et al., 2001).

Results achieved in table (2) agreed with the results reported by (Hafez, 2003), (Zohri et al., 2014) and (Morshdy et al., 2015) who determined that Aspergillus spp and Penicillium spp were the 
most predominant mould species isolated from meat products samples. Occurrence of various types of moulds in meat products may be attributed to the condition of the environment at which the meat products prepared, beside manufacturing rooms, stores, refrigerators, which are very suitable for the development of mould on meat and inside the meat products.

Data presented in table (2) revealed the dominant of Aspergillus and Penicillium spp. in all examined spices samples was in accord with the results of (Farghaly, 2006), (Hashem and Alamri 2010) and (Hammami et al., 2014) who stated that Aspergillus and Penicillium spp. were the main components of spices.

Aspergillus is a uniquitous soil-dwelling fungus. Human infections are usually acquired by inhalation of airborne spores from inanimate sources. Pulmonary aspergillosis can present as different forms, including pulmonary aspergilloma, chronic necrotizing pulmonary aspergillosis, invasive pulmonary aspergillosis and allergic bronchopulmonary aspergillosis, depending on the atopic and immune status of the host and the site of involvement within the respiratory system (Wong et al., 2008).

These isolated strains of Aspergillus species in table (3) were obtained by (Brr et al., 2004) isolated A. flavus, A.niger. A.fumigatus, A. parasiticus and A, terreus from kofta and burger, (Morshdy et al., 2015) isolated A. flavus, A.niger, A .fumigatus and A. parasiticus from kofta and burger. While in spices the obtained results were in agreement with those reported by (Elshafie et al., 2002) isolated A. flavus, A. niger. (Farghaly 2006) found the predominant identified Aspergillus species were; A. niger, A.flavusvarcolumnaris, A.flavus Link and A. parasiticus. (Aziz and Youssef 2009) detected A. flavus (24 isolates), and A. parasiticus (16 isolates) from 100 samples of spices. (El-Ghreeb et al., 2013) declared that Aspergillus was the most predominant genus which identified into six species. A. niger and A. flavus were the most common Aspergillus. (Abdo et al., 2017) proved that A. niger was the prevalent followed by A. flavus, A.ochraceus, A.candidus and A.gluacus. The chronic exposure to aflatoxin well above the FDA guideline 20 (ppb) affects many organs; however, the major target organ is liver. Aflatoxins are hepatotoxic in humans and animals. Food- related exposures to AFs and the resulting aflatoxicosis can range from acute to chronic, and illness can range from mild to severe, including development of cirrhosis (severe liver damage) and may result in development of liver cancer. Aflatoxin B1 is the most potent known natural carcinogen (FDA 2013). Aflatoxin is resistant to heating and freezing processes and can remain in these products until consumption (Maktabi et al., 2016).

Results achieved in table (4) nearly similar with the results obtained by (Shaltout et al. 2014) found that the average concentration of aflatoxin B1 $(\mu \mathrm{g} / \mathrm{kg})$ in kofta were $13.38 \pm 1.52$. While (Abd-Elghany and Sallam 2015) revealed that aflatoxins (AF) levels ranged from 0.55 to 7.5 with a mean value of $3.22 \pm 0.43 \mu \mathrm{g} / \mathrm{kg}$ in beef burger samples (Aziz and Youssef 2009) said that the contamination of processed meat with aflatoxin was shown to correlate with the addition of spices to fresh meat.

The occurrence of aflatoxins in processed meat was related to the addition of spices to fresh meat (Aziz and Youssef, 2009). Aflatoxins are linked with carcinogenicity in humans and animals (Bennett and Klich, 2003). The adverse effect of aflatoxins on consumers depends on the level and time of exposure, age, gender, health state, strength of immunity, diet and environmental factors (Negash, 2018).

According to the safe permissible limits stated by WHO (Jelinek et al., 1989) permissible limits 15 ppb. Table (5) indicated that all examined samples (100\%) were accepted samples within the permissible limits. The Food and Agriculture Organization (FAO) determined the maximal 
daily intake of aflatoxin B1 to be $5 \mu \mathrm{g} / \mathrm{kg}$ and the total aflatoxin $(\mathrm{B} 1+\mathrm{B} 2+\mathrm{G} 1+\mathrm{G} 2)$ to be 10 $\mu \mathrm{g} / \mathrm{kg}$. This toxin has been classified by the International Agency for Research on Cancer (IARC) (2010), in carcinogenic effect Group 1.

\section{CONCLUSION}

Kofta, burger and their spices highly contaminated with Aspergillus spp and Penicillium spp which may gain access during the manufacturing process or food additives leading to high economic losses and have a public health hazard due to the production of Aflatoxins. A. flavus and A. niger were the most predominant Aspergillus spp isolated from meat products and their spices, Aspergillus flavus is considered the main cause of meat products spoilage, leading to severe economic losses and comprises a public health problem due to the production of Aflatoxins so, rigorous hygienic procedures must be applied during the manufacturing process. Aflatoxin B1 the main Aflatoxin occurred in spices.

The result demonstrates the fact that the unhygienic and poor sanitary conditions under which the meat and meat products are handled and processed are not acceptable from sanitary point of view. It has further evidence that the undesirable level of contamination which might have acquired from the environment and agents and to obtain wholesome,

safe and sound meat products, the principles Good Manufacturing Practices (GMP) and Hazard Analysis and Critical Control Point (HACCP) must be adopted.

\section{REFERENCES}

Abd-Elghany, S.M. and Sallam, K.I., 2015. Rapid determination of total aflatoxins and ochratoxins A in meat products by immuno-affinity fluorimetry. Food chemistry, 179, 253-256.
Abdo, N.G., Khafaga, I.N., El-Hariri, M and Refai, K.M., 2017. Detection of fungi and total aflatoxins in food additives and some meat products by serological and molecular biological methods. Journal of the Egyptian Veterinary Medical Association, 177(2), 153-173.

Alcaide-Molina, M., Ruiz-Jiménez, J., MataGranados, J.M. and de Castro, M. L., 2009.High through-put aflatoxin determination in plant material by automated solid-phase extraction on-line coupled to laser-induced fluorescence screening and determination by liquid chromatography-triple quadrupole mass spectrometry. Journal of Chromatography A, 1216(7), 1115-1125.

APHA., 2001.American Public Health Association: Compendium of methods for the microbiological examination of foods. 4th Ed. Eds.Downes, F.P. and K. Ito. Sheridan Books Inc.,Washington D.C., USA.

Arx -Von, J.A., 1967.Pilzkunde, J. Gramer. Inder. A.R. Geneter Velag Rommandit Cessellschaft.FI.9490.

Aziz, N.H. and Youssef, A.Y., 2009. Occurrence of aflatoxins and aflatoxin-producing moulds in fresh and processed meat in Egypt. Journal of Food Additives and Contaminants.8 (3): 321-331.

Bennett, J.W. and Klich, M., 2003. Mycotoxins. Clinical Microbiological Reviews, 16 : 516-497

Bhatnagar, D., Yu, J. and Ehrlich, K.C., 2002. Toxins of filamentous fungi. Chemical immunology, 81 :167 - 206.

Brr, H.A., Moustafa, Y.N and Edris, M.A., 2004. Incidence of moulds and aflatoxiins in 
some meat products. Benha veterinary medical journal., 15(2): 65-75.

El-Ghreeb, W.R., Darwish, W.S., Tharwat, A.E., EL-Desoky, K.I. and Hussein, M.A., 2013. Aflatoxin and Ochratoxin A residues in some meat additives. Life Science Journal, 10(4):3411-3416.

Elshafie, A.E., Al-Rashdi, T.A., Al-Bahry, S.N. and Bakheit, C.S., 2002. Fungi and aflatoxins associated with spices in the Sultanate of Oman. Mycopathologia., 155(3): 155-160.

Farghaly, R. M., 2006. Occurrence and significance of moulds and their mycotoxins in spices as meat additives. Benha veterinary medical journal. 17(2): 35-46.

Food and Agriculture Organization of the United Nations and Food and Drug Administration "FDA"., 2013. Bad bug book: Foodborne pathogenic microorganisms and natural toxins handbook, 2nd ed. US Food and Drug Administration, Silver Spring, P. 87-92: 232-292.

Fratamico, P.M., Bhunia, A.K. and Smith, J.L. (Eds.)., 2005. Foodborne pathogens: microbiology and molecular biology. Horizon Scientific Press.

Gaafer, R. M. H. 2009. Quality Evaluation of Ready to Eat Meat Products in Alexandria Governorate. M.V.SC. Thesis, Faculty Vet. Med .Alexandria Univ.

Gabal, M.A., Hegazy, S.M. and Hassanien, N,Y.,1994. Aflatoxin Production by Aspergillus flavus field isolates. Vet. Human Toxicol, 36: 519-512.

Hafez, A.T., 2003. Mould decontamination in Egyptian meat products handled at room temperature. Ph. D. thesis (Food Hygiene), Faculty of Veterinary Medicine, Suez Canal University.

Hammami, W., Fiori, S., Al Thani, R., Kali, N.A., Balmas, V., Migheli, Q., Jaoua, S., 2014. Fungal and aflatoxin contamination of marketed spices. Food control, 37, 177181.

Hashem, M. and Alamri, S., 2010. Contamination of common spices in Saudi Arabia markets with potential mycotoxinproducing fungi. Saudi journal of biological sciences, 17(2), 167-175.

International Agency for Research on Cancer. , 2010. Agents classified by the IARC monographs, vol 1-100. WHO, Fransa.

Isleyici O., 2017. The most important mycotoxins, characteristics and the factors influencing formation. Turkiye Klinikleri J Food Hyg. Technol- Special Topics, 3, 1-12.

ISO (217-1-2:2008) "International Standards Organization EAST AFRICAN STANDARD: Microbiology of food and animal feeding stuffs - Preparation of test samples, initial suspension and decimal dilutions for microbiological examination- Part 1-3: Specific rules for the preparation of meat and meat products, 2008.

Jelinek, C.F.; Ponland, A.E. and Wood, G.E. (1989): Worldwide occurrence of mycotoxins in foods and feeds - An update. J.A.O.A.C., 72: 223-230.

Koburger, J. A. and Marth, E., 1984. Yeast and Mould. In: Compendium of Methods for the Microbiological Examination of Food, Speck M. L. (Ed.) American Public Health Association, Washington D. C. 
Kocić-Tanackov, S.D., Dimić, G.R. and Karalić, D., 2007. Contamination of spices with moulds potential producers of sterigmatocystine. Acta Periodica Technologica, (38), 29-35.

Lamada, H.M. and Nassif, M.Z., 2008. Mycological profile of meat product, with special reference to aflatoxins. 9th Vet. Med. Zag. Conference (20-22 August 2008) Port-Said.

Little, C.L., Omotoye, R., Mitchell, R.T., 2003. The microbiological quality of ready-toeat foods with added spices. International journal of environmental health research, 13(1), 31-42.

Maktabi, S., Fazlara, A., Ghorbanpoor, M., Talayol, G. and Siavashi, M., 2016. Measurement and assessment of aflatoxin B1 and its producing moulds in Iranian sausages and burgers. J. Kermanshah Univ. Med. Sci. 20(2): 7478.

Martins, M.L., Martins, H.M. and Bernardo, F., 2001. Aflatoxins in spices marketed in Portugal. Food Additives and Contaminants. 18 (4): 315-319.

Morshdy, M.A., Hussien, A.M., ElAbbasy, T.M. and Elzwahery, M.R., 2015.Aflatoxins residues in some meat products. 2nd Vet. Med. Suez Canal. Conference of Food Safety, I: 90-95.

Negash, D., 2018. A review of aflatoxin: occurrence, prevention, and

gaps in both food and feed safety. Journal of Applied Microbiol Res, 1: 35-43

Peromingo B., Rodriguez A., Bernaldez V., Delgado J., Rodriguez M., 2016. Effect of temperature and water activity on growth and aflatoxin production by Aspergillus flavus and Aspergillus parasiticus on cured meat model systems. Meat Science, 122, 76-83.

Pitt, J.I. and Hocking, A.D., 2009. Fungi and Food spoilage. 3rd Ed. Published by Springer Dordrecht Heidelberg London New York.

Pleadin J., Kovacevic D., Perkovic I., 2015. Impact of casing damaging

on aflatoxin B1 concentration during the ripening of dry-fermented

meat sausages. Journal of Immunoassay Immunochem, 36: 655- 666.

Rajić, A., Waddell, L.A., Sargeant, J.M., Read, S., Farber,J., Firth, M.J. and Chambers, A., 2007. An overview of microbial food safety programs in beef, pork, and poultry from farm to processing in Canada. Journal of Food Protection, 7 (5):1286-1294.

Saleh, M.A. and Salah El-Dien, W.M., 2006. Evaluation of fungi in minced and some meat products in Zagazig City markets. Zagazig veterinary medical journal.34 (3): 10- 16.

Scott, De.B., 1965.Toxigenic fungi isolated from cereal and legume products. Mycopathol. Mycol. Appl. 25: 213-222.

Shaltout, A.F., Amin, A.R., Nassif, Z.M. and Abd-Elwahab, A.S., 2014. Detection of aflatoxins in some meat products', Benha veterinary medical journal. 27 (2): 368374.

Stubblefield, R.D., William, F.K. and Stoloff, L., 1982. Determination and TLC confirmation of identity of Aflatoxin B1 and M1 in artificially contaminated beef liver. J. Assoc. Off. Analy. Chem., 65 (6): 1435. 
Svanström, A., 2013. Trehalose metabolism and stress resistance in Aspergillus niger. SLU Service/Repro, Uppsala, Sweden.

Taniwaki, M.R., Silva, N.D., Banhe, A.A. and lamariaika, B.I., 2001. Comparison of culture media, simplate and petrifilm for enumeration of yeasts and moulds in foods. Journal of Food Protect .64 (10): 1592-1596.
Wong, C.F., Yan, S.W. and Chan, K.W., 2008. Report of two cases of tumour-like blocked pulmonary cavities with liquid content infected with aspergilli, a rare form of pulmonary aspergillosis. Respirology (13), 306-308.

Zohri, A.A., Moharram, M.A. and Refaie, R.S.., 2014. Mycobiota contaminating beef burger and sausage with reference to their toxins and enzymes. Journal of Basic and Applied Mycology 5: 61-73. 